\title{
REBUILDING THE MINAMI-GAMO WASTEWATER TREATMENT PLANT DEVASTATED BY THE GREAT EAST JAPAN EARTHQUAKE AND TSUNAMI
}

\author{
Kimimasa KATO ${ }^{1}$, Hikaru NISHIZAKA ${ }^{2}$, Kouken KOUNOTO $^{3}$ and Masataka KUDO ${ }^{4}$ \\ ${ }^{1}$ Director, Minami-gamo Wastewater Treatment Plant, Construction Bureau, City of Sendai \\ (Gamo-Hachiroubeiyachi-Daini, Miyagino-ku, Sendai, Miyagi 983-0002, Japan) \\ E-mail:kimimasa_katou@city.sendai.jp \\ ${ }^{2}$ Technical Officer, Minami-gamo Wastewater Treatment Plant, Construction Bureau, City of Sendai \\ (Gamo-Hachiroubeiyachi-Daini, Miyagino-ku, Sendai, Miyagi 983-0002, Japan) \\ E-mail: hikaru_nishizaka@city.sendai.jp \\ ${ }^{3}$ Director, Sewerage and Pipeline Coordination Section, Construction Bureau, City of Sendai \\ (3-7-1 Kokubuncho, Aoba-ku, Sendai, Miyagi 980-8671, Japan) \\ E-mail: kouken_kounotou@city.sendai.jp \\ ${ }^{4}$ Senior Director, Sewerage and Pipeline Department, Construction Bureau, City of Sendai \\ (3-7-1 Kokubuncho, Aoba-ku, Sendai, Miyagi 980-8671, Japan) \\ E-mail: masataka_kudou@city.sendai.jp
}

\begin{abstract}
Minami-Gamo Wastewater Treatment Plant (MGWTTP) is the most important facility for the Sendai City sewerage system. The plant treats about 70 percent of the municipal wastewater from Sendai City. On March 11th, 2011, the plant was devastated by the Great East Japan Earthquake and the ensuing tsunami. Its foundation was heavily damaged. Sedimentation and aeration tanks were bent. Most of the mechanical and electrical equipment became flooded by seawater and were washed away. MGWTTP completely lost its wastewater treatment function. Due to this damage, the Sendai City Government decided that MGWTTP could not be repaired and instead should be rebuilt as a brand-new wastewater treatment plant (WTTP). In order to maintain a sanitary environment in Sendai during the construction of the new WTTP, a temporary municipal wastewater treatment was required to meet the effluent standard BOD of $60 \mathrm{mg} / \mathrm{l}$ as proposed by the National Sewerage Disaster Countermeasures Committee of the Ministry of Land, Infrastructure, Transport and Tourism. Therefore, the government implemented a mid-level treatment employing a contact oxidation with string media. MGWTTP became the largest WTTP that adopted this method in Japan. Operating the mid-level treatment facility, the new MGWTTP was completed five years after the Great East Japan Earthquake. In this paper, the process until the completion of the new MGWTTP is outlined. The Sendai Declaration of Sewerage Works Disaster Risk Reduction, which was adopted at the 2015 Sendai Symposium, is also introduced.
\end{abstract}

Key Words: rebuilding, build back better, temporary wastewater treatment, the Great East Japan Earthquake, tsunami

\section{INTRODUCTION}

Sendai is an urban city that is balanced with nature and serves as the political and economic center of Tohoku (the northeast region of the island of Honshu in Japan). Greenery is especially abundant in the center of the city, which has lush zelkova tree-lined streets and parks.

Sendai's sewerage system takes its origin from the
Yotsuya Artificial Ditch that was constructed by DATE Masamune, the first lord of Sendai Clan. The ditch supplied clean water from the Hirose River (a river flowing through central Sendai) to urban areas and carried wastewater out of the city.

Sendai is the first city that was allowed to construct a modern sewerage system by the Japanese Government. In 1891, the Sendai City Government started surveying and thereafter began construction 
Table 1 Designated wastewater quantities of MGWTTP before the Great East Japan Earthquake.

\begin{tabular}{|c|c|}
\hline Average Daily Flow $\left(\mathrm{m}^{3} /\right.$ day $)$ & 360,000 \\
\hline Maximum Daily Flow $\left(\mathrm{m}^{3} /\right.$ day $)$ & 434,000 \\
\hline Maximum Hourly Flow $\left(\mathrm{m}^{3} / \mathrm{h}\right)$ & 26,000 \\
\hline
\end{tabular}

Table 2 Information about the Earthquake.

\begin{tabular}{|l|l|}
\hline $\begin{array}{l}\text { Earthquake } \\
\text { Name }\end{array}$ & $\begin{array}{l}\text { The 2011 off the Pacific } \\
\text { coast of Tohoku Earthquake }\end{array}$ \\
\hline $\begin{array}{l}\text { Date and Time } \\
\text { of Occurrence }\end{array}$ & $\begin{array}{l}\text { March 11th, 2011 at 2:46 } \\
\text { p.m. }\end{array}$ \\
\hline Epicenter & $\begin{array}{l}\text { Off the Sanriku Coast (about } \\
130 \mathrm{~km} \text { east-southeast of } \\
\text { Oshika Peninsula; depth of } \\
\text { about 24 km) }\end{array}$ \\
\hline Magnitude & 9.0 \\
\hline
\end{tabular}

on the sewerage works plan, which was finished in 1899 after the cities Tokyo and Osaka. In 1957, a 20 -year sewerage works plan covering 3,900 hectares of municipal area, including the construction of Minami-Gamo Wastewater Treatment Plant (MGWTTP), was prepared. Wastewater has been collected and treated at MGWTTP since 1964.

In 1972 the previous plan was revised to cover an area of 8,419 hectares. After subsequent revisions and mergers with neighboring municipalities, the sewerage service expanded to the current area of 18,437 hectares. An activated sludge process was introduced at MGWTTP in 1979. In 2011, the MGWTTP treated about $360,000 \mathrm{~m}^{3} /$ day of wastewater (see Table 1). The plant had been treating about $70 \%$ of wastewater from Sendai City's $1,080,000$ people.

Before the Great East Japan Earthquake, we had experienced many earthquakes in Japan, such as the Miyagi Prefecture Earthquake in 1978, Great Hanshin Earthquake in 1995, Niigata Chuetsu Earthquake in 2004, and so on. These earthquakes heavily damaged the sewerage system; for example, they caused fractures in sewerage pipes and joints. Although the damaged sewerage system was strengthened to a much stronger system against earthquakes, with the Great East Japan Earthquake we could not avoid the devastation of sewerage system because of the subsequent, unexpected massive tsunami. Most of the mechanical and electrical equipment became flooded by seawater and were washed away. Therefore, we had to adopt a new process to repair the damaged sewerage system and update it to a new system in order to avoid the devastation caused by tsunami. In this paper, the new process, which took into account disaster prevention and risk reduction, was adopted in the reconstruction

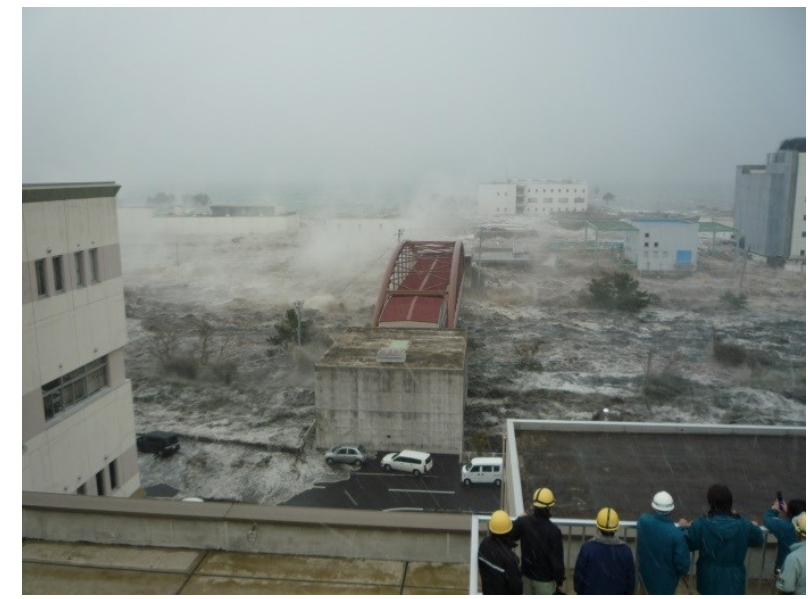

Fig. 1 MGWTTP at the moment it was hit by the tsunami.

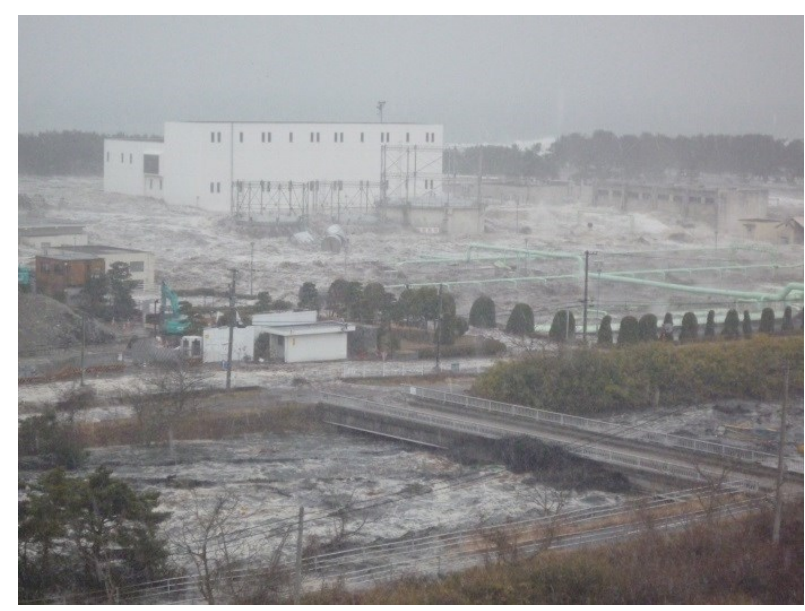

Fig. 2 Submerged MGWTTP.

as described below.

\section{INFORMATION ABOUT THE GREAT EAST JAPAN EARTHQUAKE}

Information about the Great East Japan Earthquake is shown in Table 2. The earthquake that occurred off the Sanriku Coast on March 11th, 2011 at a magnitude of 9.0 was the largest earthquake in Japan's recorded history and the fourth largest in the recorded history of the world. In Sendai, a maximum seismic intensity of upper 6 on the Japanese intensity scale was recorded. This caused enormous damage including landslides in the hilly areas, collapsed roads and buildings, and the disruption of vital utilities.

An ensuing tsunami hit MGWTTP about one hour after the earthquake (Fig. 1). Most facilities were submerged in seawater (Fig. 2).

\section{DAMAGE TO SEWERAGE FACILITIES}

The earthquake and tsunami caused an unprece- 
dented amount of damage to sewerage facilities in Sendai City. Although there were concerns about wastewater overflow in the urban area, sanitary conditions were maintained. Wastewater could be transported to MGWTTP even during the power outage, because of the natural gravity due to the location of the urban area of Sendai on the Sendai plain field to the coastal area where the WTTP is located.

The earthquake and tsunami also destroyed MGWTTP. Its foundation and primary sedimentation tank were heavily damaged (Fig. 3). Final sedimentation and aeration tanks became tilted. The wall of a pumping station building was bent by a 10-metre-high tsunami (Fig. 4). At MGWTTP most of the mechanical and electrical equipment were flooded with seawater (Fig. 5) and washed away. The MGWTTP completely lost its wastewater treatment functions.

\section{THE DISASTER RECOVERY PROJECT OF MINAMI-GAMO WASTEWATER TREATMENT PLANT}

\section{(1) Initial responses to the earthquake and tsu- nami}

The Sendai City Government prepared a disaster manual in 2006, and updated it in 2010 to include a business continuity plan (BCP). More than a hundred municipal employees and contractors were working at the time of the disaster. They were safe due to their quick evacuation based on the BCP (Fig. 6).

MGWTTP was originally designed so that municipal wastewater could be treated and discharged by taking advantage of the natural downward gravity from the city area to the WTTP. Therefore, MGWTTP was able to receive wastewater from the municipal area without consuming a lot of energy and treated it by sedimentation and disinfection. In order to discharge the water, we had to open an emergency discharge gate. However, the gate was designed to be operated using electricity. Therefore, we manually opened the gate at $10 \mathrm{~cm}$ interval. Fortunately, due to this, we could discharge the collected wastewater. However, we had to break the gate (Fig. 7) later in order to completely prevent wastewater overflow in the Sendai City municipal area. This contributed to the continuation of our sewage service and preserved the public sanitation in Sendai.

(2) The restoration policy for Minami-gamo wastewater treatment plant

In June 2011, the restoration policy committee for

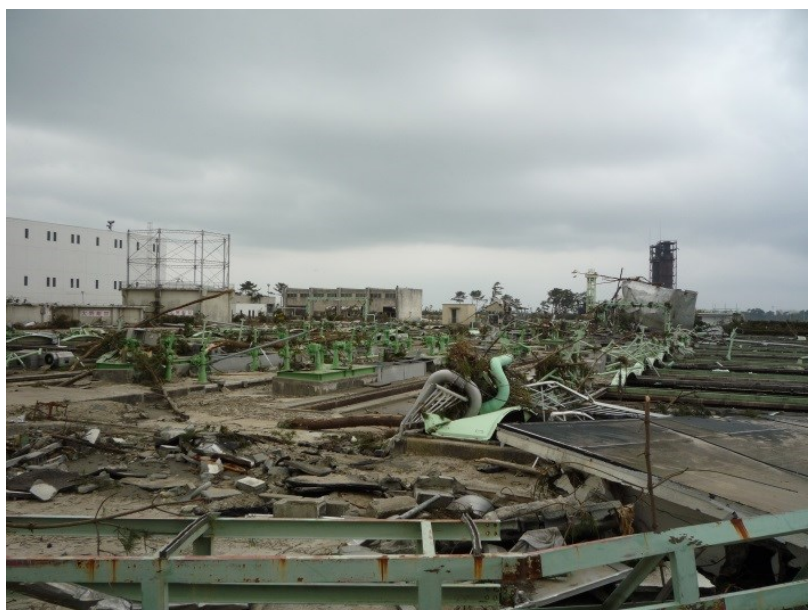

Fig. 3 The damaged primary sedimentation tank.

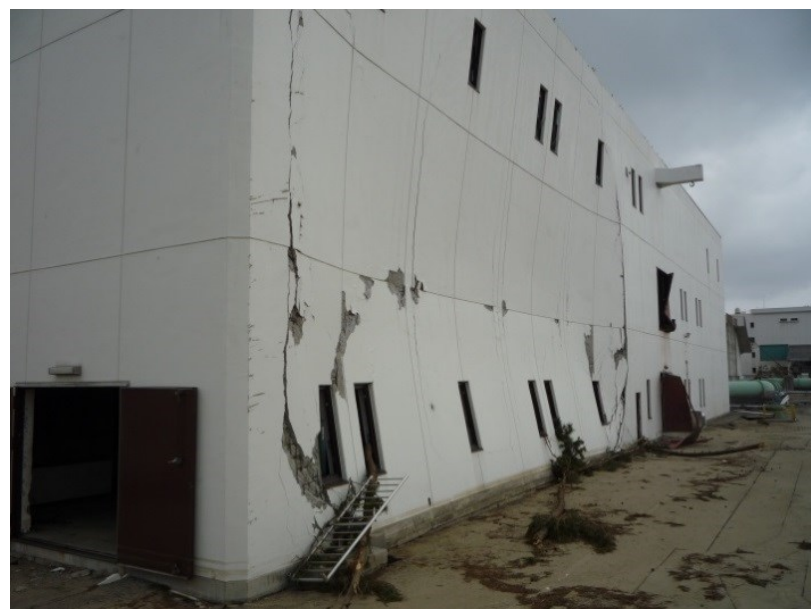

Fig. 4 The pumping building's wall bent by the tsunami.

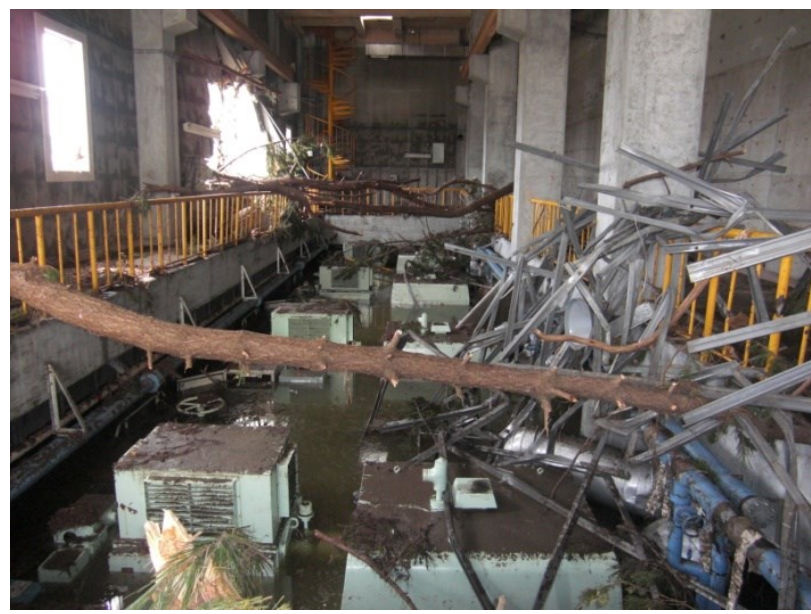

Fig. 5 Flooded equipment in the pumping station building.

MGWTTP was established to discuss whether the plant could be rebuilt into a new plant or not. In order to formulate restoration policies, they considered the expense for the restoration, introduction of tsunami countermeasures, and treatment method of wastewater from Sendai City during the restoration. The committee proposed the following restoration policies $^{1)}$ on September 15th:

a) The elevation difference between an urban area 
and the coastal area is critical to operate MGWTTP. This is extremely beneficial from a crisis management standpoint during a disaster to maintain public sanitation, and thus we suggested preserving these characteristics during the rebuilding process.

b) Rebuilding the wastewater treatment facilities will take at least five years. During this period of constructing the new plant, MGWTTP will treat municipal wastewater with temporary facilities. The quality of treated water should be summarily improved during the period of temporary treatment. Considering the cost of maintenance and management, we decided to adopt a contact oxidation process as the temporary treatment method.

c) Considering the ability to preserve simple treatment functions through the natural flow of wastewater, the location of the sludge handling facility, the amount of time needed for restoration, and the cost of this project, we recommended that rather than relocating or decentral-

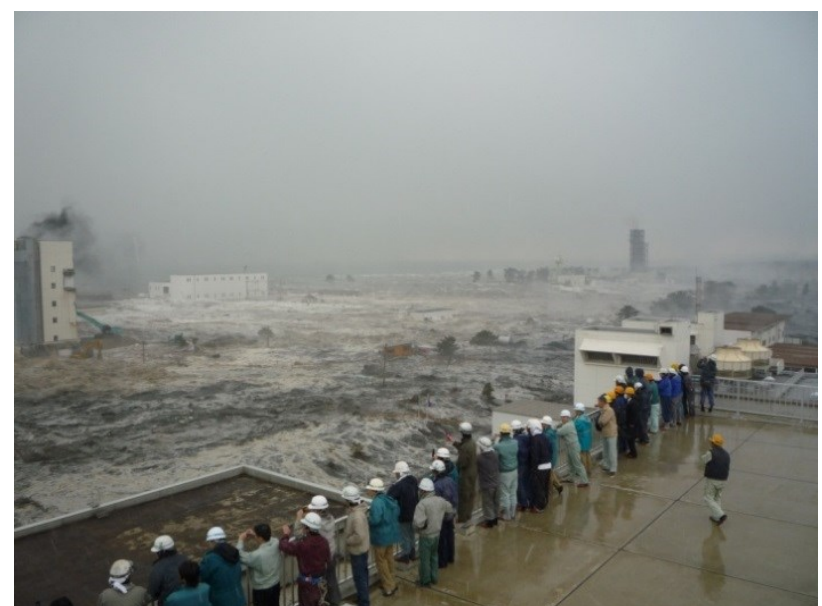

Fig. 6 Employees escaped to the roof of an administration building.

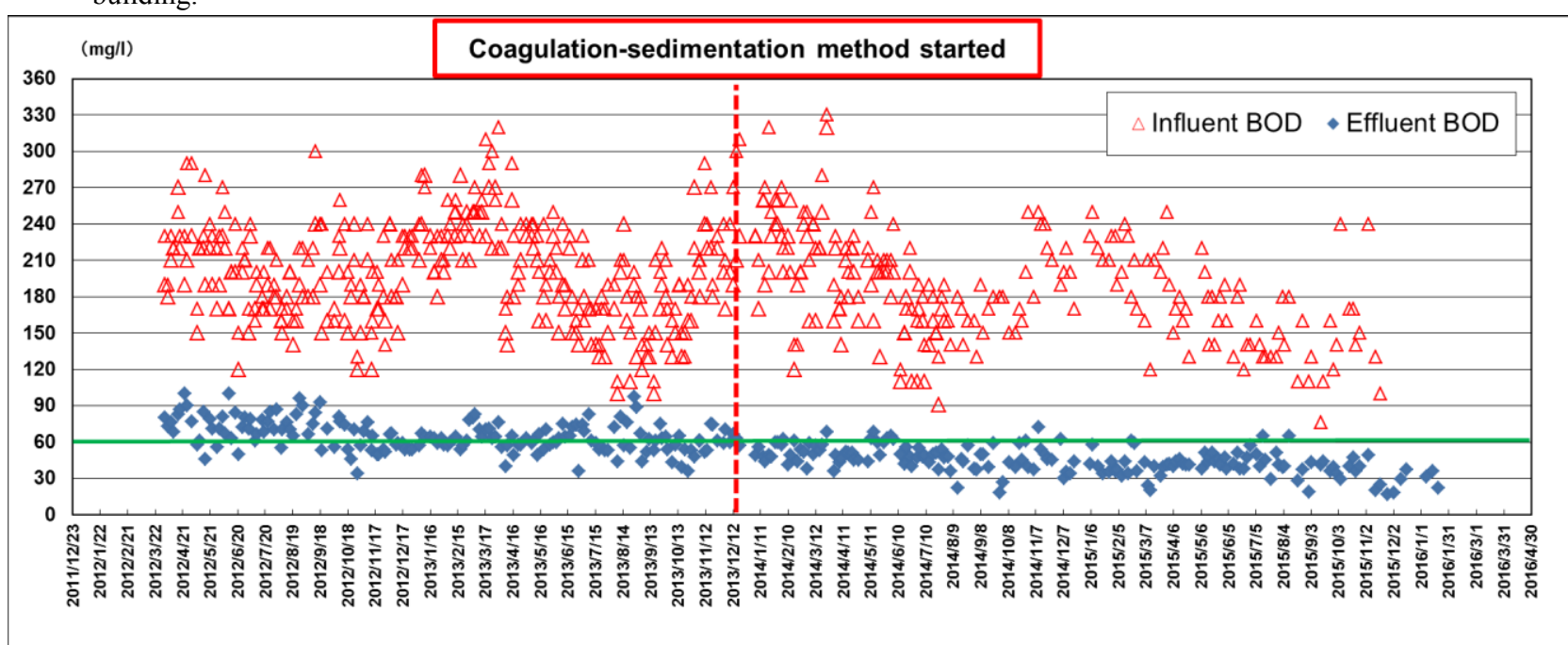

Fig. 8 The Influent and Effluent BOD of the temporary wastewater treatment. izing the wastewater treatment facility, it is more rational and economical to restore the facility on its current site or in the vicinity.

d) In order to prevent structural damage by a tsunami and to design it in such a way to preserve functioning equipment, it is necessary to adopt tsunami countermeasures, such as building a facility based on the recorded height of the tsunami caused by the Great East Japan Earthquake. Additionally, measures should be taken to protect workers from tsunami by building suitable evacuation areas.

e) After considering tsunami countermeasures, construction time, project cost, and maintenance and management, we concluded that the wastewater treatment facility should be restored on its current site.

f) In order to secure electric power in a disaster and reduce the burden on the environment, we recommended introducing energy-saving equipment and solar and small hydroelectric power generators. Furthermore, new technologies for the re-

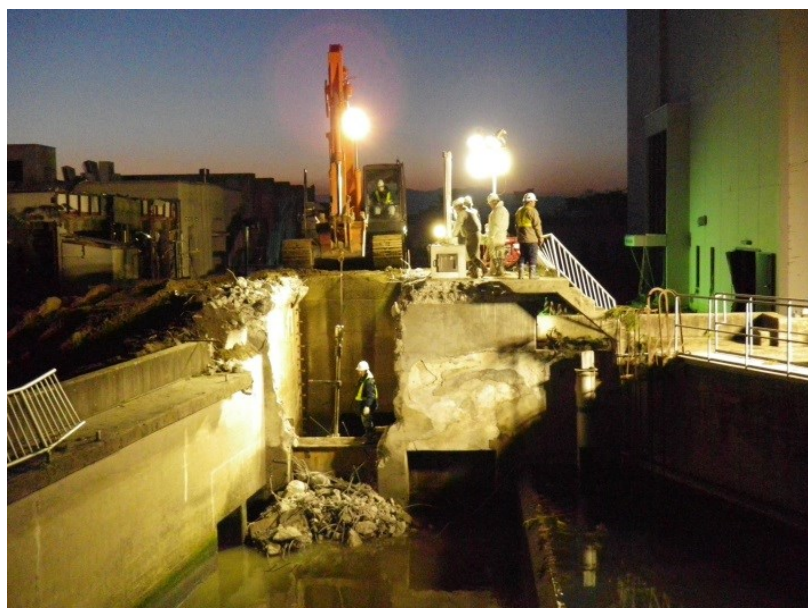

Fig. 7 Breaking the emergency discharge gate of MGWTTP.

.


cycling of resources at the sewerage works, energy saving, energy generation, and reducing the burden on the environment should be introduced in the midto long-term after analyzing the cost-benefit effects on business.

\section{(3) Rebuilding Minami-gamo wastewater treat- ment plant}

After reviewing the committee's proposals, the Sendai City Government judged that MGWTTP could not be rebuilt to its original form and decided to rebuild MGWTTP as a new WTTP. The features of the new facility are as follows:

a) Like the previous facility, the structure allows for simple treatment (sedimentation, disinfection, and discharge) through the natural flow of wastewater, even if electricity is lost in a disaster.

b) While preserving the previous function, the primary and final sedimentation tanks are double-layered. The reactor tank is deepened to increase its height in order to make the facility resilient to tsunami.

c) We reduce the burden on the environment by introducing solar and small hydroelectric power generators. These are also used as a part of emergency power sources in a disaster.

\section{(4) Temporary wastewater treatment by contact oxidation process}

Based on the proposal, a treatment process was investigated, which would meet the upper limit of the temporary effluent standard of the Biochemical Oxygen Demand (BOD) of $60 \mathrm{mg} / 1$ as proposed by the National Sewerage Disaster Countermeasures Committee of the Ministry of Land, Infrastructure, Transport and Tourism. This process was settled in pre-aeration and primary sedimentation tanks before the earthquake. Accordingly, as a measure to gradually improve the quality of effluent at MGWTTP, we implemented mid-level treatment through contact oxidation with string media (Table 3). MGWTTP became the largest WTTP in Japan to adopt this method.

The process has operated since April 2012. The effluent BOD successfully decreased (Fig. 8). However, effluent BOD has exceeded the temporary effluent standard during peak hours. In order to keep the effluent BOD stably below $60 \mathrm{mg} / \mathrm{l}$ (which was the temporary effluent standard), we introduced a coagulation-sedimentation method in December 2013.

\section{(5) Managing construction for disaster recovery}

While it commonly takes 10 years to build a wastewater plant with processing capacity of $433,000 \mathrm{~m}^{3} /$ day, we were required to fully rebuild
Table 3 Facility outline of the contact oxidation.

\begin{tabular}{|l|l|}
\hline Treatment process & $\begin{array}{l}\text { Biological Contact } \\
\text { Oxidation using a bio- } \\
\text { film method with string } \\
\text { media }(68 \text { units/tank) }\end{array}$ \\
\hline Design flow & $300,000 \mathrm{~m}^{3} /$ day \\
\hline $\begin{array}{l}\text { Design influent and } \\
\text { effluent BOD (tempo- } \\
\text { rary standard) }\end{array}$ & $177 \mathrm{mg} / 1$ and $60 \mathrm{mg} / \mathrm{l}$ \\
\hline $\begin{array}{l}\text { Hydraulic retention } \\
\text { time }\end{array}$ & $50 \mathrm{~min}$ \\
\hline $\begin{array}{l}\text { BOD volumetric load- } \\
\text { ing }\end{array}$ & $5.2 \mathrm{~kg}-\mathrm{BOD} / \mathrm{m}^{3} / \mathrm{day}$ \\
\hline Ventilation equipment & $\begin{array}{l}\text { GM Blower }\left(260 \mathrm{Nm}^{3}\right. \\
\times 400 \mathrm{~kW} \times 2 \mathrm{units})\end{array}$ \\
\hline Reactor tank & $\begin{array}{l}4 \text { channels } \times 2 \mathrm{pools}^{3} \\
\left(\text { Volume: } 102,000 \mathrm{~m}^{3}\right)\end{array}$ \\
\hline
\end{tabular}

our plant in only five years. Therefore, we needed to have superior organization to execute this plan.

For example, the construction field was divided into five areas and a manager was assigned to each area. In November 2014, mechanical and electrical equipment for the building began to be installed, along with continued construction. To avoid delay in the construction schedule, a coordination council meeting was held every week.

A safety managerial division was established to ensure the safety of a total of (at its highest number) 1,300 people, including staff members and service contractors. Safety checks and patrols continued every day.

An alarm system, which automatically gave warnings using five audio speakers in the plant in the event of an earthquake, was set up. Emergency tsunami drills were conducted every six months.

\section{(6) Start of operation and acclimation}

The acclimation of half of the reconstructed facilities started in November 2015. These facilities could treat $200,000 \mathrm{~m}^{3}$ of wastewater every day. Due to the huge scale of our facilities, the acclimation did not use seed sludge. Activated sludge grew from organic matter in inflow wastewater. However, the hydrologic parameter of each tank was different; thus, a trial-and-error adjustment was needed. The quality of treated water achieved the effluent standard BOD of $15 \mathrm{mg} / 1$ in January 2016. In March 2016, all reconstructed wastewater treatment facilities were completed. 


\section{THE 2015 SENDAI SYMPOSIUM ON SEWERAGE WORKS DISASTER RISK REDUCTION}

The Third United Nations (UN) World Conference on Disaster Risk Reduction was held in Sendai from March 14th to 18th 2015, drawing 6,500 delegates from 187 nations to the conference. The conference included discussions about a disaster risk reduction and reconstruction.

Shinzo Abe, Prime Minister of Japan, and Ban Ki-moon, Secretary-General of the UN, emphasized the concept of "build back better". The conference adopted the Sendai Framework for Disaster Risk Reduction 2015-2030 and Sendai Declaration. The framework and declaration included the importance of investing in disaster reduction and an implementation guide with a multi-stakeholder approach.

In terms of the sewerage works, the 2015 Sendai Symposium on Sewerage Works Disaster Risk Reduction was co-hosted as a public forum by the Ministry of Land, Infrastructure, Transport and Tourism, Miyagi prefecture, Japan Sewage Works Association, and the Sendai City Government on March 17th and 18th. The following events were held at the symposium: tours of damaged wastewater treatment plants at Minami-gamo and Sen-en, exhibits on sewerage works disaster risk reduction, a discussion regarding the reconstruction of MGWTTP, introduction of domestic and international disasters, and a panel discussion with delegates from Peru and New Zealand (Fig. 9). Through these events, Sendai Declaration of Sewerage Works Disaster Risk Reduction has been shared with the world. The Sendai Declaration affirms actions toward disaster risk reduction in sewage works in order to mitigate the human, social, economic, and environmental losses that are caused by disasters, thereby agreeing with the concept of "build back better" and the Sendai Framework for Disaster Risk Reduction 2015-2030. Sendai City will internationally contribute and cooperate towards the realization of a sustainable society.

The Sendai Declaration of Sewerage Works Disaster Risk Reduction adopted at the 2015 Sendai Symposium on Sewerage Works Disaster reads as follows:

On March 17th and 18th, 2015, we sewerage professionals assembled in Sendai City, Miyagi Prefecture, a city currently recovering from the Great East Japan Earthquake and Tsunami of March 11th, 2011. We express our deepest sympathies to the many victims of the earthquake and tsunami and express our gratitude for the great outpouring of support from around the world to the affected areas.

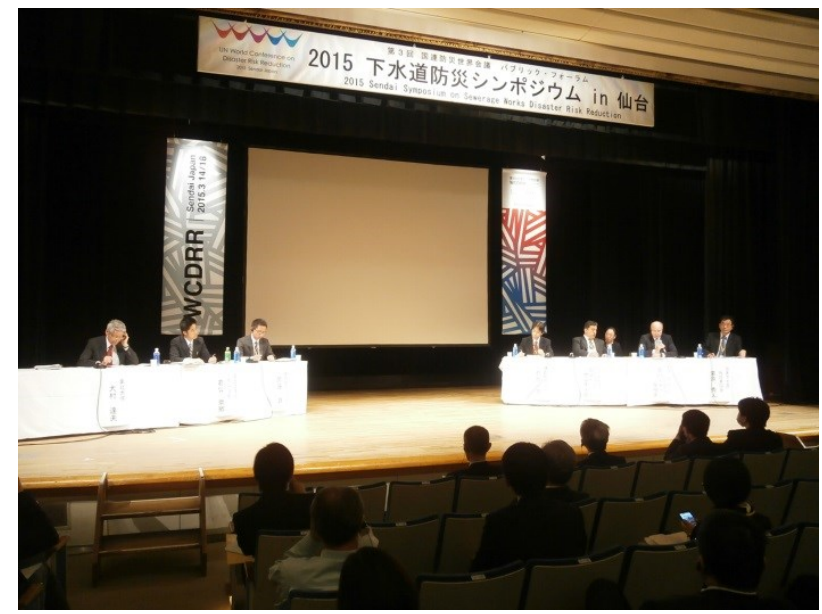

Fig. 9 A panel discussion in the 2015 Sendai Symposium on Sewerage Works Disaster Risk Reduction.

Until now we have been conducting various disaster risk reduction measures. Although it is impossible to fully prevent damage in the event of such unprecedented disasters such as the Great East Japan Earthquake and Tsunami, we have confirmed that it is possible to greatly mitigate impacts not only by taking preliminary "hard" (structural) measures, but also by implementing "soft" (non-structural) measures. The former "hard" measures are the earthquake proofing of sewerage facilities, securing equipment, materials and fuel for use in emergencies, and so on. The "soft" measures are formulating $\mathrm{BCP}$, providing mutual assistance when disasters occur and training citizens. In view of the growing global risks posed by large-scale disasters, it is necessary to further strengthen and enhance structural and non-structural countermeasures.

Furthermore, from the restoration and reconstruction following the disaster, we have learned the importance of returning valuable resources such as energy and biomass from sewers to the local community and contributing to global environmental conservation and sustainable society through implementing energy-saving measures and utilizing renewable energy.

By widely sharing various examples, experiences, and lessons of post-disaster restoration and reconstruction at the 2015 Sendai Symposium on Sewerage Works Disaster Risk Reduction, we hope to further the cause of disaster risk reduction and mitigation. For this reason, from now on, we need to actively share information and cooperate internationally. At the same time, we must actively implement sewerage initiatives geared toward mitigating the human, social, economic, and environmental losses that are caused by disasters.

From this viewpoint, we make the following declarations to the world concerning the reduction of disaster risks in sewerage systems. 
a) Declaration concerning the importance of "hard" structural disaster countermeasures

We will contribute to the construction of a robust society by continuing to promote "hard" measures for sewerage networks and facilities such as earthquake proofing and tsunami proofing in light of the lessons of the Great East Japan Earthquake and Tsunami.

b) Declaration concerning the importance of "soft" non-structural disaster countermeasures

We will strive to secure, develop, and maintain citizen knowledge in the sewerage sector and mitigate the impact of large-scale disasters through mutual aid.

c) Declaration concerning the importance of restoring facilities in the short-term to medium-term

We will quickly restore sewerage functions at times of disaster and provide the valuable resources of working sewerage systems for supporting the regeneration and reconstruction of communities and industries.

d) Declaration concerning the importance of facility restoration and the long-term approach to sewerage systems

By conducting restoration and reconstruction, we will contribute to the realization of a sustainable society through promoting energy-saving initiatives and the utilization of renewable energy.

e) Declaration concerning the importance of information sharing and international cooperation

We will contribute to the realization of safe and congenial societies in the world through broadly sharing and providing our experiences and the lessons we learned about sewerage damage, restoration and reconstruction, and stay actively involved in international cooperation concerning technology and sharing know-how for disaster risk reduction.

\section{CONCLUSIONS}

MGWTTP was destroyed by the Great East Japan Earthquake and the ensuing tsunami in March 2011. Although more than a hundred staff were working in the plant at that time, all employees were safe due to their quick evacuation based on the standing BCP.
However, MGWTTP completely lost its wastewater treatment function.

In September 2011, the restoration policy committee for MGWTTP proposed a plan to rebuild the facility. Based on this plan, the Sendai City Government decided to rebuild the plant as a new WTTP. While constructing the new plant, MGWTTP treated municipal wastewater temporarily. The quality of treated water was gradually improved during the period of temporary treatment. The contact oxidation process was operated in April 2012. Then, the effluent BOD successfully decreased. In order to keep the effluent BOD stably below $60 \mathrm{mg} / 1$ (which was the temporary effluent standard,) the coagulation-sedimentation method was introduced in December 2013.

In terms of the new WTTP, the acclimation of half of the reconstructed facilities was started in November 2015 without seed sludge. The quality of treated water achieved the effluent standard BOD of $15 \mathrm{mg} / \mathrm{l}$ in January 2016. In March 2016, all the reconstructed wastewater treatment facilities were completed.

We learned important lessons from the disaster and restoration. First, we should emphasize countermeasures against tsunami. Second, a restoration policy and a construction management system are needed in times of major disasters.

We strongly hope that our experience during the five years after the earthquake and tsunami described in this paper contributes to the prevention and restoration of disaster and damage, which may be caused by an unexpected huge earthquake like the Great East Japan Earthquake. Lastly, we will continue to internationally disseminate the Sendai Declaration of Sewerage Works Disaster Risk Reduction adopted in the 2015 Sendai Symposium on Sewerage Works Disaster.

\section{REFERENCES}

1) Construction Bureau, City of Sendai: Restoration and Reconstruction of Sendai Wastewater Utility after the Great East Japan Earthquake, 2013.

2) Construction Bureau, City of Sendai: The Third United Nations (UN) World Conference on Disaster Risk Reduction. 2015 Sendai Symposium on Sewerage Works Disaster Risk Reduction Report, 2015.

(Received January 16, 2017) 